OPEN ACCESS

Edited by:

William Valentine Williams, BriaCell Therapeutics Corp.,

United States

Reviewed by:

Andaleeb Sajid,

Yale University, United States

Wei-Chien Huang,

China Medical University, Taiwan

${ }^{*}$ Correspondence: Jing Ma

majing.1988.ok@163.com

Song-Qiang Xie

xiesq@henu.edu.cn

Dong Fang

emailfangdong@163.com

Specialty section:

This article was submitted to Pharmacology of Anti-Cancer Drugs,

a section of the journal

Frontiers in Pharmacology

Received: 28 June 2020 Accepted: 19 October 2020 Published: 25 November 2020

Citation:

Wang $X$, Liang $C$, Yao $X$, Yang $R-H$, Zhang Z-S, Liu F-Y, Li W-Q, Pei S-H,

Ma J, Xie S-Q and Fang D (2020)

PKM2-Induced the Phosphorylation of

Histone $\mathrm{H} 3$ Contributes to EGF-

Mediated PD-L1 Transcription in HCC.

Front. Pharmacol. 11:577108.

doi: 10.3389/fphar.2020.577108

\section{PKM2-Induced the Phosphorylation of Histone H3 Contributes to EGF-Mediated PD-L1 Transcription in HCC}

\author{
Xiao Wang ${ }^{1}$, Chao Liang ${ }^{1}$, Xin Yao ${ }^{1}$, Ruo-Han Yang ${ }^{1}$, Zhan-Sheng Zhang ${ }^{1}$, Fan-Ye Liu ${ }^{1}$, \\ Wen-Qi $\mathrm{Li}^{1}$, Shu-Hua Pei ${ }^{1}$, Jing Ma ${ }^{1 *}$, Song-Qiang Xie ${ }^{1,2 *}$ and Dong Fang ${ }^{1 *}$ \\ ${ }^{1}$ Institute for Innovative Drug Design and Evaluation, School of Pharmacy, Henan University, Kaifeng, China, ${ }^{2}$ Institute of Chemical \\ Biology, School of Pharmacy, Henan University, Kaifeng, China
}

High expression of programmed death-ligand-1 (PD-L1) in hepatocellular carcinoma (HCC) cells usually inhibits the proliferation and functions of $T$ cells, leading to immune suppression in tumor microenvironment. However, very little has been described regarding the mechanism of PD-L1 overexpression in HCC cells. In the present study, we found epidermal growth factor (EGF) stimulation promoted the expression of PD-L1 mRNA and protein in HCC cells. Inhibition of epidermal growth factor receptor (EGFR) could reverse EGF-induced the expression of PD-L1 mRNA and protein. Subsequently, we also observed that the phosphorylation level of Pyruvate kinase isoform M2 (PKM2) at $\mathrm{Ser}^{37}$ site was also increased in response to EGF stimulation. Expression of a phosphorylation-mimic PKM2 S37D mutant stimulated PD-L1 expression as well as H3-Thr ${ }^{11}$ phosphorylation in HCC cells, while inhibition of PKM2 significantly blocked EGF-induced PD-L1 expression and H3-Thr ${ }^{11}$ phosphorylation. Furthermore, mutation of $\mathrm{Thr}^{11}$ of histone $\mathrm{H} 3$ into alanine abrogated EGF-induced $\mathrm{mRNA}$ and protein expression of PD-L1, Chromatin immunoprecipitation (ChIP) assay also suggested that EGF treatment resulted in enhanced $\mathrm{H} 3-\mathrm{Thr}^{11}$ phosphorylation at the PD-L1 promoter. In a diethylnitrosamine (DEN)-induced rat model of HCC, we found that the expression of phosphorylated EGFR, PKM2 nuclear expression, H3-Thr ${ }^{11}$ phosphorylation as well as PD-L1 mRNA and protein was higher in the livers than that in normal rat livers. Taken together, our study suggested that PKM2-dependent histone $\mathrm{H} 3-\mathrm{Thr}^{11}$ phosphorylation was crucial for EGF-induced PD-L1 expression at transcriptional level in HCC. These findings may provide an alternative target for the treatment of hepatocellular carcinoma.

Keywords: epidermal growth factor, Pyruvate kinase isoform M2, histone H3, programmed death-ligand-1, hepatocellular carcinoma

\section{INTRODUCTION}

Hepatocellular carcinoma (HCC) is one of the most common cancers worldwide with a high mortality rate ( $\mathrm{Du}$ et al., 2016; Nie et al., 2018). Immune escape is emerging as important contributors to the pathogenesis of HCC through remodeling the tumor microenvironment (Liu et al., 2018a; Mantovani et al., 2020). Aberrant overexpression of programmed death-ligand-1 (PDL1) has been observed in hepatocellular carcinoma cells (Zhong et al., 2017). Unfortunately, PD-L1 
expression by cancer cells usually inhibits the proliferation and functions of $\mathrm{T}$ cells in tumoral microenvironment, leading to immune suppression and impressive antitumor effects (Langhans et al., 2019; Liao et al., 2019). However, the mechanism of PD-L1 upregulation in HCC remains largely unclear.

The epidermal growth factor receptor (EGFR) belongs to the ErbB family of receptor tyrosine kinases (RTKs) (Patel and Leung, 2012; Maennling et al., 2019). Hyperactivation of EGFR in HCC is suggested to be associated with aggressive tumors, metastasis, and poor patient survival (Berasain and Avila, 2014; Lanaya et al., 2014). Numerous studies have showed that EGF/EGFR signal could increase PD-L1 expressions in non-small-cell lung cancer, colon cancer stem cells, renal cancer cells and glioblastoma (Li et al., 2018b; Chen et al., 2019b; Ma et al., 2020; Su et al., 2020). Therefore, this raise the possibility that EGF/EGFR signal is also attributable to the upregulation of PD-L1 in HCC.

Pyruvate kinase isoform M2 (PKM2) is a rate-limiting enzyme in glycolysis that plays a key role in tumor metabolism (Xie et al., 2016; Liu et al., 2017). Interestingly, under EGF stimulation, PKM2 can translocate to the nucleus and act as a transcriptional co-activator of many target genes associated with tumor cell growth and metastasis (Yang et al., 2011; Chen et al., 2019c). For example, PKM2 could translocate to nucleus and phosphorylate histone $\mathrm{H} 3$ at $\mathrm{Thr}^{11}$ residue in response to the activation of EGFR, leading to the expression of CCND1 and MYC at transcriptional level (Yang et al., 2012a). Notably, recent findings showed that PKM2 was closely positively related to PDL1 expression in lung adenocarcinoma and colon carcinoma (Palsson-McDermott et al., 2017; Guo et al., 2019), while knockdown of PKM2 substantially inhibited PD-L1 expression in lung cancer cells (Guo et al., 2019). Although the expression of PKM2 was higher in HCC tissues than in adjacent tissues (Lv et al., 2018), it is still unknown whether PKM2 was involved in regulating PD-L1 expression in HCC. In the present study, we found that PKM2-induced phosphorylation of histone $\mathrm{H} 3$ is required for EGFR-mediated PD-L1 transcription in hepatocellular carcinoma.

\section{MATERIALS AND METHODS}

\section{Materials}

All the inhibitors used in the present study were purchased from Cell Signaling Technology (Beverly, MA, USA). Rabbit monoclonal anti-PD-L1 antibody (ab205921), rabbit monoclonal anti-PKM2 antibody (ab206130), rabbit polyclonal anti-Histone $\mathrm{H} 3$ antibody (ab1791), rabbit polyclonal antiHistone H3 (phosphor-Thr ${ }^{11}$ ) antibody (ab5168) were obtained from Abcam (Cambridge, MA, USA). Rabbit polyclonal anti-PKM2 (phosphor-Ser ${ }^{37}$ ) antibody (PA5-37684) obtained from Thermo Fisher Scientific (Waltham, MA, USA). Mouse monoclonal anti- $\beta$-actin antibody (sc-47778), horseradish peroxidase (HRP)-conjugated goat anti-rabbit IgG (sc-2054) and goat anti-mouse IgG (sc-2973) were all purchased from Santa Cruz Biotechnology (Santa Cruz, CA, USA). EGF was purchased from R\&D systems (Minneapolis, MN, USA).

\section{Cell Lines and Cell Culture}

The human hepatoma cell lines SNU368, SNU739, Huh-7 and HepG2 were purchased from the Cell Bank of the Chinese Academy of Science (Shanghai, China). All the cells were routinely maintained in RPMI 1640 medium or Dulbecco's modified Eagle's medium (DMEM) supplemented with 10\% fetal bovine serum (HyClone, UT, USA) at $37^{\circ} \mathrm{C}$ in a humidified atmosphere with $5 \% \mathrm{CO}_{2}$.

\section{Induction of HCC}

Male Sprague-Dawley rats (6-week-old) were purchased from Beijing Weitong Lihua Animal Co. All animal procedures were performed in accordance with the guidelines of the Institutional Animal Care and Use Committee of Henan University (Grant No. HUSOM2018-87). To induce hepatocellular carcinoma, the rats were intraperitoneally injected diethylnitrosamine (DEN) at a dose of $50 \mathrm{mg} / \mathrm{kg}$ once a week for 16 weeks. Rats in the control group were intraperitoneally injected with normal saline solution on the same days as the DEN-treated group. At the end of the study, all animals were sacrificed, and the livers were removed. After photographing with a camera, the livers were kept at $-80^{\circ} \mathrm{C}$ for qRT-PCR or Western blotting.

\section{RNA Extraction and qRT-PCR}

mRNA from cancer cells or rat livers were isolated using TRIzol reagent (Invitrogen, Carlsbad, CA, USA) as previous described (Li et al., 2018a). Reverse transcription was performed by using random hexamers and MMLV reverse transcriptase according to the manufacturer's instructions (Takara, Tokyo, Japan). Relative quantitative real-time PCR was performed in triplicate for each sample using $2 \times$ SYBR Green PCR Master Mix (Promega) on an ABI 7500 sequence detection system (Applied Biosystems). Glyceraldehyde phosphate dehydrogenase (GAPDH) was used as an internal control. The relative expression level of the genes was calculated by the $2^{-\Delta \Delta \mathrm{Ct}}$ method. Specific primers for human hepatocellular carcinoma cells were as follows: PD-L1, forward: 5'-TGT CAG TGC TAC ACC AAG GC-3' , reverse: $5^{\prime}$-ACA GCT GAA TTG GTC ATC CC-3'. GAPDH, forward: $5^{\prime}$-GAC ACC CAC TCC TCC ACC TTT- $3^{\prime}$, reverse: $5^{\prime}$-TTG CTG TAG CCA AAT TCG TTGT- $3^{\prime}$. Specific primers for rat were as follows: PDL1, forward: 5' -TTA TAG TCA CAG CCT GCA GTC ACG -3', reverse: 5'-ATC GTG ACA TTG CTG CCA TAC TC-3'; GAPDH, forward: $5^{\prime}$-AGC CAT GTA CGT AGC CAT CC-3', reverse: $5^{\prime}$-GCC ATC TCT TGC TCG AAG TC-3'.

\section{Western Blot Analysis}

Western blot analysis was conducted as previously described (Liu et al., 2018b). Briefly, the total proteins were extracted using icechilled RIPA lysis buffer containing $50 \mathrm{mM}$ Tris- $\mathrm{HCl}(\mathrm{pH} \mathrm{8.0)}$, $150 \mathrm{mM} \mathrm{NaCl}, 0.5 \%$ sodium deoxycholate, $0.1 \%$ SDS, $1 \% \mathrm{NP}-40$, $5 \mathrm{mM}$ EDTA, $0.25 \mathrm{mM}$ PMSF and protease inhibitor cocktail. The nuclear proteins were isolated according to previous report. In brief, the harvested cells were washed three times with cold phosphate buffered saline (PBS) buffer and then resuspended gently in hypotonic buffer containing $20 \mathrm{mM}$ Tris- $\mathrm{HCl}$ ( $\mathrm{pH} 7.4$ ), $10 \mathrm{mM} \mathrm{NaCl}$ and $3 \mathrm{mM} \mathrm{MgCl}$. After incubation on ice for $15 \mathrm{~min}$, these cells were lysed with a Dounce homogenizer. 
The homogenate was centrifuged to remove intact cells, followed by centrifugation at $800 \mathrm{~g}$ to collect the nuclei. The supernatant contains the cytoplasmic fraction. The nuclear pellets were washed three times with PBS buffer and lysed through sonication. The concentration of total or nuclear protein was determined using a BCA assay kit (Pierce, Rockford, IL). Protein samples were denatured and separated by SDS-polyacrylamide gel electrophoresis (SDS-PAGE). Following separation, the protein was transferred onto a PVDF membrane. The membranes were then blocked with $5 \%$ nonfat milk or $3 \%$ BSA followed by the incubation of the indicated primary and HRP-conjugated secondary antibodies. The blots were detected using the ECL plus reagents and visualized using a Fluor Chem E Imager (Protein Simple, San Jose, CA, USA).

\section{ELISA Assay}

Supernatants from cancer cell cultures were collected at the indicated time points after EGF stimulation. The content of PD-L1 in the culture medium was measured using ELISA kits (R\&D Systems, Minneapolis, MN) according to the instructions provided by the manufacturer. Absorbance was measured at $450 \mathrm{~nm}$ by using a Vmax Kinetic microplate reader (Molecular Devices, Sunnyvale, CA).

\section{Immunofluorescence}

The immunofluorescence staining was performed as previously described (Bi et al., 2019). Briefly, Cells grown on coverslips were stimulated with EGF for indicated times and fixed for $10 \mathrm{~min}$ in $4 \%$ paraformaldehyde at room temperature. After blocked with $5 \%$ fetal calf serum for $1 \mathrm{~h}$ at room temperature, the cells were stained with the corresponding primary antibody overnight at $4{ }^{\circ} \mathrm{C}$, followed by incubation with Alexa Fluor 488-conjugated secondary antibodies (Invitrogen, Carlsbad, CA, USA) for $1 \mathrm{~h}$ at room temperature. Nuclei were labeled with Hoechst 33342 stain for $5 \mathrm{~min}$ at room temperature. Images were captured using an LSM510M (Carl Zeiss) confocal microscope.

\section{Chromatin Immunoprecipitation}

Chromatin immunoprecipitation (ChIP) assays were performed using a Simple ChIP plus enzymatic chromatin IP Kit (Cell Signaling Technology) following the manufacturer's instructions. In brief, cells were cross-linked with $1 \%$ formaldehyde for $10 \mathrm{~min}$ at $37^{\circ} \mathrm{C}$. Then the chromatin was digested with micrococcal nuclease to generate 150-900 bp DNA/protein fragments. The DNA-protein complexes were immunoprecipitated with the ChIP-grade antibodies and appropriate protein G-agarose beads. Normal rabbit or mouse IgG was used as a negative control. The ChIP samples were verified by qPCR to evaluate histone modification status on the PD-L1 promoter, and the primers were as follows (-1,178 bp to $-1,117 \mathrm{bp}$ ): forward $5^{\prime}$-GCT GGG CCC AAA CCC TATT - $3^{\prime}$ and reverse $5^{\prime}$-TTT GGC AGG AGC ATG GAG TT-3'.

\section{Statistical Analysis}

Statistical analyses were performed using the GraphPad Prism 8.0 (GraphPad Software, Inc., CA, USA). All data are presented as means \pm SEM. The statistical significance of the difference between the two groups was tested by an unpaired, two-tailed Student's $t$-test. One-way analysis of variance (ANOVA) followed by Tukey or Dunnet's post-tests were used to compare means of multiple experimental groups. $p<0.05$ was considered to be significant.

\section{RESULTS}

\section{Activation of EGFR Promotes PD-L1 Transcription in HCC Cells}

To determine whether the activation of EGFR was responsible for the upregulation of PD-L1 in HCC, we treated Huh-7, HepG 2, SNU-368 and SNU-739 cells with $100 \mathrm{ng} / \mathrm{ml}$ EGF and then measured the mRNA and protein expression of PD-L1. Through real time PCR, we found that EGF promoted the mRNA expression of PD-L1 in these cancer cells (Figure 1A). Similarly, incubation of HCC cells with $100 \mathrm{ng} / \mathrm{ml}$ EGF also induced a significant increase in PD-L1 protein expression (Figure 1B). Considering that PD-L1 is a secreted protein, we also examined the content of PD-L1 in cell culture medium. As shown in Figure 1C, the level of PD-L1 in cell culture medium increased in EGF-treated group.

Given that EGF-induced PD-L1 mRNA expression in SNU368 cells was more significant than in other cell lines, we subsequently select SNU-368 cells to explore the underlying mechanism of EGF-induced PD-L1 expression at transcriptional level. In order to determine whether the activation of EGFR contributes to the upregulation of PD-L1 in HCC cells, we first knocked down of EGFR with specific shRNA in SNU-368 cells and evaluated the expression of EGFmediated PD-L1 expression. Our real time PCR results showed that knockdown of EGFR could block EGF-induced the upregulation of PD-L1 mRNA and protein expression in SNU-368 cells (Figures 2A,B). Then, we examined the effects of Gefitinib, an inhibitor of EGFR tyrosine kinase, on PD-L1 expression in EGF-treated SNU-368 cells. As expected, exposure of SNU-368 cells to $20 \mu \mathrm{M}$ Gefitinib for $12 \mathrm{~h}$ could attenuate the upregulation of $\mathrm{PD}-\mathrm{L} 1 \mathrm{mRNA}$ and protein expression induced by EGF (Figures 2C,D). Obviously, EGF can promote the mRNA and protein expression via activation of EGFR in HCC cells.

\section{Phosphorylation of PKM2 at Ser ${ }^{37}$ Is Required for EGF-Induced PD-L1 Expression}

It has been reported that the phosphorylation of PKM2 at $\mathrm{Ser}^{37}$ is required for its nuclear translocation upon EGFR activation, leading to a series of gene expression (Yang et al., 2012b). Based on this report, we supposed that the phosphorylation of PKM2 at $\mathrm{Ser}^{37}$ may be involved in EGF-induced PD-L1 expression. To test this hypothesis, we first treated SNU-368 cells with $100 \mathrm{ng} / \mathrm{ml} \mathrm{EGF}$ and then detected the level of PKM2 $\mathrm{Ser}^{37}$ phosphorylation. The results showed that EGF could induce a significant upregulation of PKM2 $\mathrm{Ser}^{37}$ phosphorylation in SNU-368 cells (Figure 3A). Then, we asked if EGFR inhibitor 

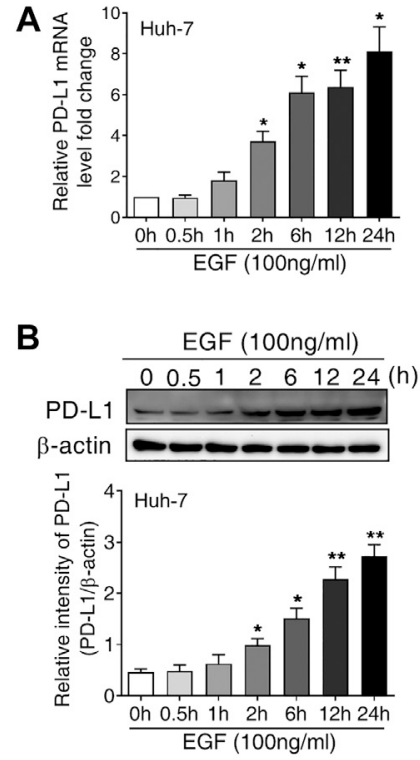

C

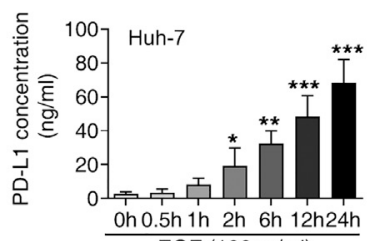

EGF $(100 \mathrm{ng} / \mathrm{ml})$
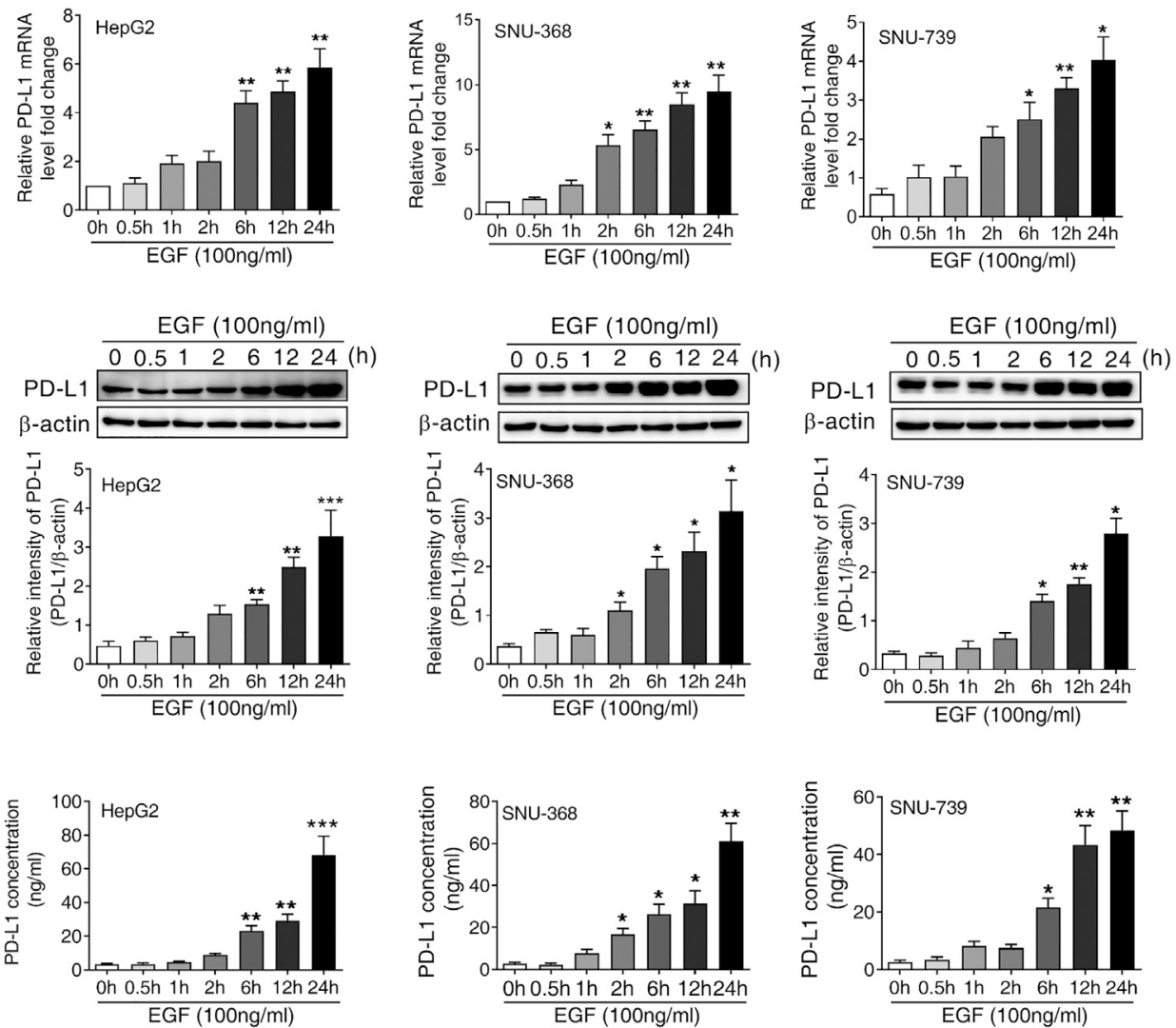

FIGURE 1 | EGF promotes PD-L1 expression in hepatocellular carcinoma cells (A and B) A significant increase in PD-L1 mRNA (A) and protein expression (B) was observed in Huh-7, HepG2, SNU-368 and SNU-739 cells after treated with EGF for indicated time. ${ }^{*} p<0.05$, ${ }^{* *} p<0.01,{ }^{* * *} p<0.001$ compared to control group, oneway ANOVA, $n=5$ independent experiments per group (C) The ELISA assay showed that the concentration of PD-L1 in the cell culture medium was increased after incubation with EGF for indicated time, ${ }^{*} p<0.05,{ }^{* *} p<0.01,{ }^{* * *} p<0.001$ compared to control group, one-way ANOVA, $n=5$ independent experiments per group.

Gefitinib could reverse EGF-induced PKM2 Ser ${ }^{37}$ phosphorylation. The results indicated that $20 \mu \mathrm{M}$ Gefitinib almost completely abolished $100 \mathrm{ng} / \mathrm{ml}$ EGF-induced PKM2 $\mathrm{Ser}^{37}$ phosphorylation after $2 \mathrm{~h}$ coincubation in SNU-368 cells (Figure 3B). Moreover, using a Western blot assay, we also observed increased PKM2 nuclear accumulation in SNU-368 cells after treated with $100 \mathrm{ng} / \mathrm{ml}$ for $2 \mathrm{~h}$, while $20 \mu \mathrm{M}$ Gefitinib blocked $100 \mathrm{ng} / \mathrm{ml}$ EGF-induced PKM2 nuclear accumulation (Figure 3C). Immunofluorescence analysis further confirmed these results (Figure 3D).

Subsequently, we examined the effects of PKM2 knockdown on EGF-induced PD-L1 expression in SNU-368 cells. Using real time PCR and Western blot assay, we found that knockdown of PKM2 significantly reversed EGF-induced PD-L1 mRNA and protein expression (Figures 4A,B). Furthermore, we transfected SNU-368 cells with Flag-tagged WT PKM2, a phosphorylationdefective PKM2 S37A mutant, or a phosphorylation-mimic PKM2 S37D mutant and examined the mRNA and protein expression of PD-L1. The results showed that only PKM2 S37D mutant could promote the expression of PD-L1 mRNA and protein in SNU-368 cells (Figures 4C,D). Through chromatin immunoprecipitation (ChIP) analyses, we also demonstrated that only PKM2 S37D mutant, but not WT
PKM2 or PKM2 S37A mutant, could induce an increased PKM2 binding to PD-L1 promoter in SNU-368 cells (Figure 4E). Thus, phosphorylation of PKM2 at $\mathrm{Ser}^{37}$ is essential for EGF-induced PD-L1 expression in HCC cells.

\section{PKM2-Induced Phosphorylation of Histone H3 is Involved in EGF-Mediated PD-L1 Expression in HCC Cells}

$\mathrm{PKM} 2$ has been reported to phosphorylate histone $\mathrm{H} 3$ at $\mathrm{Thr}^{11}$ site in response to EGF stimulation, which is required for subsequent gene expression (Yang et al., 2012a). Therefore, we first treated SNU-368 cells with $100 \mathrm{ng} / \mathrm{ml}$ EGF and examined the level of histone $\mathrm{H} 3 \mathrm{Thr}^{11}$ phosphorylation. The results indicated that EGF treatment increased histone H3 Thr ${ }^{11}$ phosphorylation in SNU-368 cells (Figure 5A). To investigate whether EGF-induced $\mathrm{H} 3 \mathrm{Thr}^{11}$ phosphorylation depended on PKM2, we then examined the effects of EGFR inhibitor Gefitinib and PKM2 inhibitor shikonin on EGF-induced H3 $\mathrm{Thr}^{11}$ phosphorylation. Through Western blot assay, we discovered that both Gefitinib $(20 \mu \mathrm{M})$ and Shikonin $(5 \mu \mathrm{M})$ could block EGF-mediated the upregulation of histone $\mathrm{H} 3 \mathrm{Thr}^{11}$ phosphorylation (Figure 5B). To test whether the phosphorylation of $\mathrm{PKM} 2$ at $\mathrm{Ser}^{37}$ is instrumental for histone $\mathrm{H} 3 \mathrm{Thr}^{11}$ phosphorylation, 


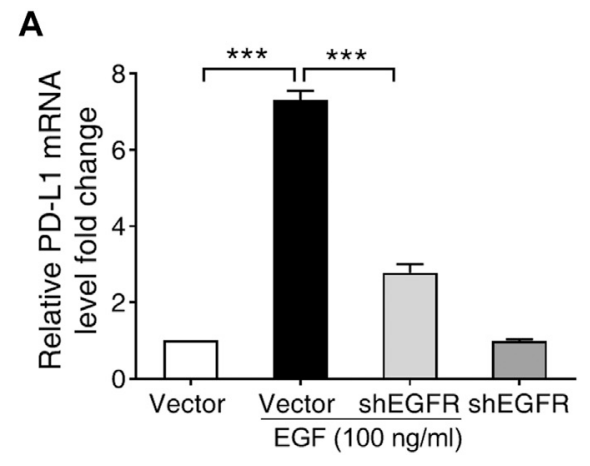

B
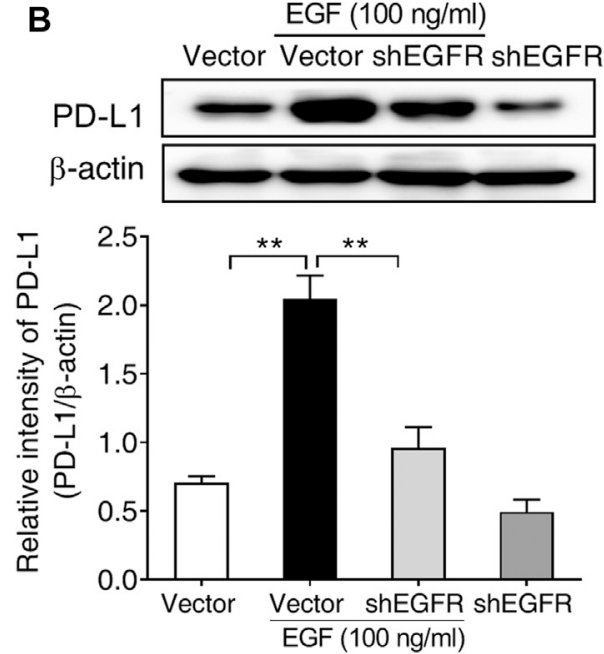

C

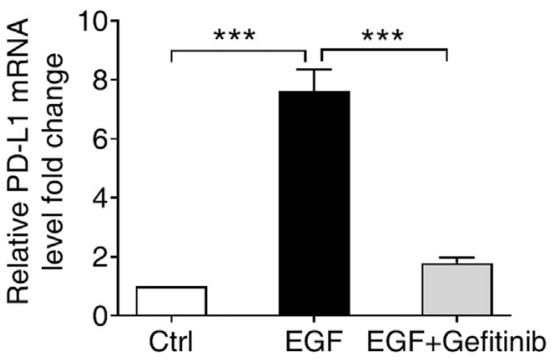

D
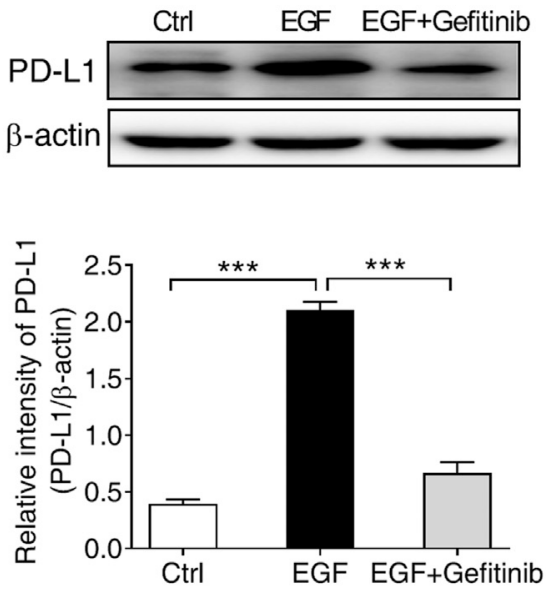

FIGURE 2 | EGFR activation is required for PD-L1 expression in SNU-368 cells. (A,B) Knockdown of EGFR with specific shRNA reversed EGF-induced PD-L1 mRNA (A) and protein (B) expressions in SNU-368 cells. At $24 \mathrm{~h}$ post-transfection, the cells were incubated in the presence or absence of $100 \mathrm{ng} / \mathrm{ml}$ EGF for $12 \mathrm{~h}$. ${ }^{\star \star} \mathrm{p}<$ $0.01,{ }^{\star \star \star} p<0.001$, one-way ANOVA, $n=4$ independent experiments per group. (C,D) EGF-induced upregulation of PD-L1 mRNA (C) and protein (D) was blocked by gefitinib. ${ }^{* \star *} p<0.001$, one-way ANOVA, $n=5$ independent experiments per group.

we expressed a Flag-tagged WT PKM2, a phosphorylation-defective PKM2 S37A mutant or a phosphorylation-mimic PKM2 S37D mutant in SNU-368 cells and measured the level of histone H3$\mathrm{Thr}^{11}$ phosphorylation. The results indicated that the phosphorylation-mimic PKM2 S37D mutant induced a higher level of histone $\mathrm{H} 3 \mathrm{Thr}^{11}$ phosphorylation compared with WT PKM2 and PKM2 S37A mutant (Figure 5C). These results suggested that phosphorylation of PKM2 at $\mathrm{Ser}^{37}$ is required to EGF-induced H3-Thr ${ }^{11}$ phosphorylation.

To investigate whether $\mathrm{H} 3-\mathrm{Thr}^{11}$ phosphorylation was involved in EGF-induced PD-L1 expression, we expressed RNAi-resistant WT histone $\mathrm{H} 3$ or histone $\mathrm{H} 3-\mathrm{T} 11 \mathrm{~A}$ in endogenous histone $\mathrm{H} 3$ depleted SNU-368 cells, the results showed that mutation of $\mathrm{Thr}^{11}$ of histone $\mathrm{H} 3$ into alanine (Ala, A) abrogated EGF-induced mRNA and protein expression of PD-L1 (Figures 5D,E). To strengthen the evidence for the causal relationship of PKM2/H3 T11 phosphorylation on PD-L1 expression, we then explored the effect of H3 T11A mutation on the PKM2 S37D overexpressioninduced PD-L1 expression in endogenous histone H3-depleted SNU-368 cells. Through real time PCR and Western blot, we found reconstituted expression of WT histone $\mathrm{H} 3$ and PKM2
S37D could induce PD-L1 mRNA and protein expression in H3depleted SNU-368 cells (Figures 5F,G), however, these increased expression of PD-L1 mRNA and protein could be blocked when WT histone $\mathrm{H} 3$ was replaced with histone $\mathrm{H} 3$ T11A mutant in endogenous histone H3-depleted SNU-368 cells (Figures 5F,G). ChIP assay also suggested that EGF treatment resulted in enhanced H3-Thr ${ }^{11}$ phosphorylation at the PD-L1 promoter (Figure 5H), while mutation of $\mathrm{Thr}^{11}$ of histone $\mathrm{H} 3$ into alanine (Ala, A) abrogated EGF-induced enhanced $\mathrm{H} 3-\mathrm{Thr}^{11}$ phosphorylation at the PD-L1 promoter in endogenous histone H3-depleted SNU368 cells (Figure 5I). These data confirmed our hypothesis that PKM2-induced H3-Thr ${ }^{11}$ phosphorylation is involved in EGFmediated PD-L1 expression in HCC cells.

In order to expand our findings in vivo, we subsequently injected diethylnitrosamine (DEN) into rats to set up a model of hepatocellular carcinoma. As the results shown in Figure 6A, numerous tumor nodules occurred in the livers of rats that received DEN administration for 16 weeks. Then, we measured the level of EGFR phosphorylation, the expression PKM2 nuclear protein and $\mathrm{H} 3-\mathrm{Thr}^{11}$ phosphorylation in these rats. The results showed that DEN treatment could induce a significant increase in 

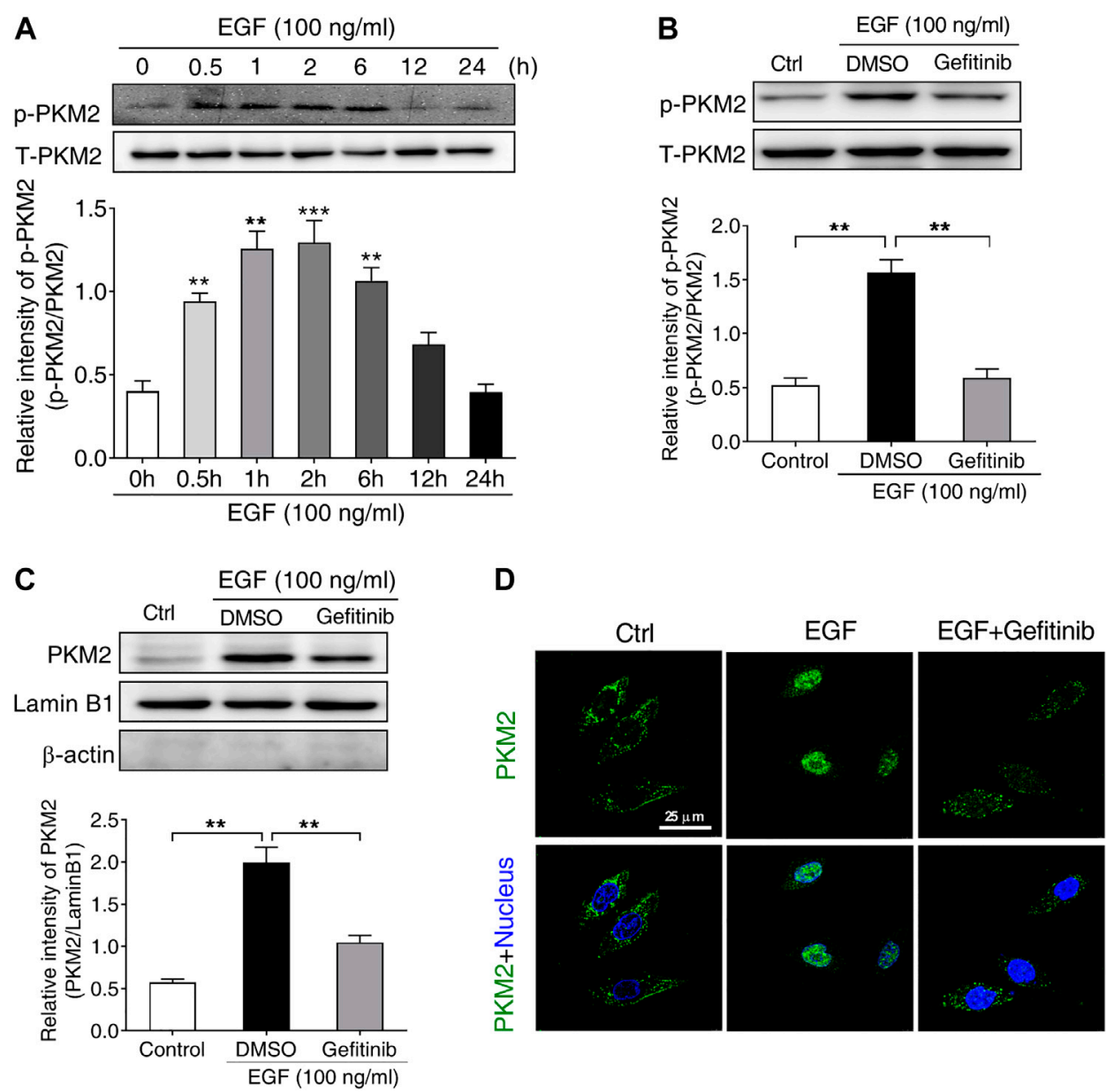

FIGURE 3 | EGF stimulates the phosphorylation and nuclear translocation of PKM2 in SNU-368 cells (A) EGF induced an increase in the level of PKM2 Ser ${ }^{37}$ phosphorylation in SNU-368 cells. ${ }^{* *} p<0.01,{ }^{* * *} p<0.001$, one-way ANOVA, $n=6$ per group (B) Gefitinib attenuated EGF-induced the level of PKM2 Ser ${ }^{37}$ phosphorylation in SNU-368 cells. ${ }^{* *} p<0.01$, one-way ANOVA, $n=5$ per group (C) EGF-mediated PKM2 nuclear accmulation was reversed by Gefitinib in SNU-368 cells. Lamin B1 was used as internal control and $\beta$-actin was used as negative control. ${ }^{* *} p<0.01$, one-way ANOVA, $n=5$ per group (D) Immunofluorescence staining showed Gefitinib attenuated EGF-induced PKM2 nuclear accmulation in SNU-368 cells.

EGFR phosphorylation, PKM2 nuclear protein and H3$\mathrm{Thr}^{11}$ phosphorylationin in the rat livers (Figures 6B-D). Moreover, we also found that the mRNA and protein expression of PD-L1 was increased in the livers of DEN-treated rats (Figures 6E,F). Meanwhile, a ChIP assay also demonstrated that DEN administration resulted in enhanced $\mathrm{H} 3-\mathrm{Thr}^{11}$ phosphorylation at the PD-L1 promoter in rats (Figure 6G). Taken together, these in vivo results also implied that $\mathrm{PKM} 2$-induced $\mathrm{H} 3-\mathrm{Thr}^{11}$ phosphorylation is involved in EGF-mediated PD-L1 expression in HCC.

\section{DISCUSSION}

High expression of PD-L1 is significantly associated with tumor aggressiveness and poor prognosis in HCC patients who were never treated via immunotherapy (Liao et al., 2019; Mocan et al., 2019). During tumor development and growth, PD-L1 can enhance immune evasion by suppression of recruitment and activation of $\mathrm{T}$ cells in tumor microenvironment (Macek
Jilkova et al., 2019). Recently, emerging evidence come to explore the underlying mechanism of PD-L1 expression in HCC. For example, osteopontin (OPN) promotes the PD-L1 expression in HCC via activation of the colony stimulating factor-1 (CSF1)-CSF1 receptor pathway in macrophages (Zhu et al., 2019). Knockdown of MYC expression can induce PD-L1 expression both at mRNA and protein levels (Zou et al., 2018). A key glycolytic enzyme, PFKFB3, mediated the increased expression of PD-L1 via activating the nuclear factor kappa $\mathrm{B}$ signaling pathway in HCC (Chen et al., 2019a). Although accumulating evidences suggested the activation of EGFR contributes to PD-L1 expression in several cancers ( $\mathrm{Li}$ et al., 2018b; Chen et al., 2019b), it is still unknown whether EGF/EGFR signal was involved in PD-L1 expression in HCC. In the present study, we also observed that EGF could induce PD-L1 expression at the transcriptional level in HCC cells, while inhibition of EGFR dramatically attenuated EGF-induced PD-L1 expression. Therefore, we supposed that EGF/EGFR signal may be critical in regulating $\mathrm{PD}-\mathrm{L} 1$ expression in many cancers. However, 

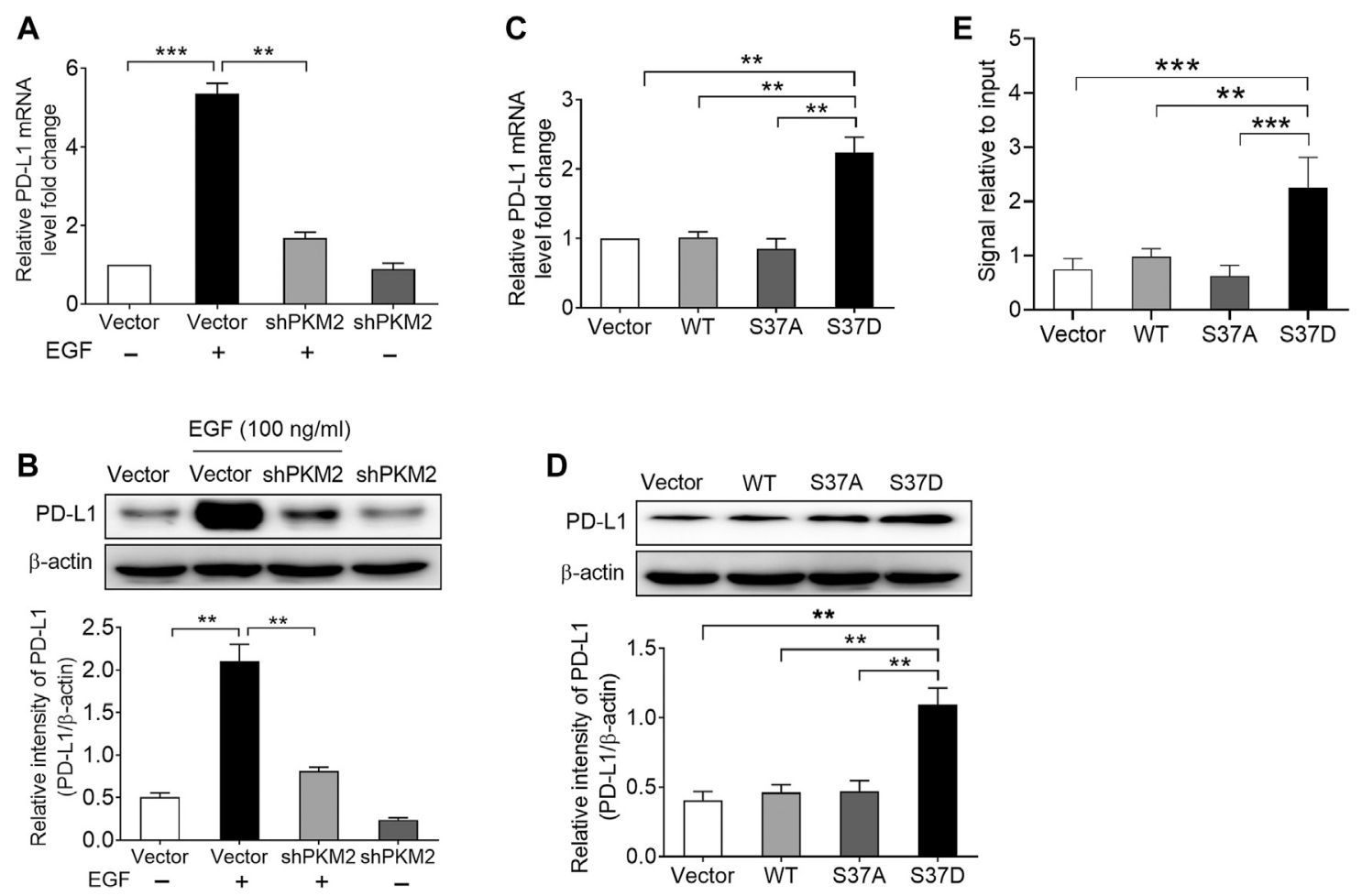

FIGURE 4 | Phosphorylation of PKM2 at Ser37 participates in EGF-induced PD-L1 expression. (A,B) PKM2 shRNA blocked EGF-induced PD-L1 mRNA (A) and protein (B) expressions in SNU-368 cells. At $24 \mathrm{~h}$ post-transfection, the cells were incubated in the presence or absence of $100 \mathrm{ng} / \mathrm{ml} \mathrm{EGF}$ for $12 \mathrm{~h}$. ${ }^{\star \star} \mathrm{p}<0.01,{ }^{\star \star \star} \mathrm{p}<$ 0.001, one-way ANOVA, $n=4$ independent experiments per group. (C,D) The expression of a phosphorylation-mimic PKM2 S37D mutant induced a higher expression of PD-L1 mRNA (C) and protein (D) compared with WT PKM2 or the S37A mutant in SNU-368 cells. ${ }^{\star \star} p<0.01$, one-way ANOVA, $n=4$ independent experiments per group. (E) ChIP analyses showed that the expression of a phosphorylation-mimic PKM2 S37D mutant resulted in increased binding of PKM2 to PD-L1 promoter in SNU-368 cells. ${ }^{*} p<0.05,{ }^{* *} p<0.01$, one-way ANOVA, $n=5$ independent experiments per group.

because we used Gefitinib to block the activity of EGFR tyrosine kinase, this may bring a risk of off targets effects due to the problem of dosage and specificity. Indeed, this is a limitation of our study.

Overexpression of PKM2 has been observed in a variety of malignant tumors, which is related to the tumor proliferation, progression and drug resistant (Wong et al., 2015; Bhardwaj and Das, 2016; Li et al., 2018c). As a glycolytic enzyme, PKM2 normally located in the cytoplasm functions as a prominent driver of the Warburg effect that plays a dominant role in cancer metabolism (Wong et al., 2015; Wang et al., 2017). In addition, PMK2 has nonmetabolic functions in malignant cells through acting as a glycolytic enzyme or transcriptional coactivator. For example, PKM2 could translocate to the nucleus and form a complex with HIF-1a subunit to promote the transcription of HIF-1a targeted genes (Azoitei et al., 2016). Nuclear dimeric PKM2 also directly phosphorylates signal transducer and activator of transcription 3 (STAT3) at $\mathrm{Tyr}^{705}$, resulting in aggressive progression of colorectal cancer (Yang et al., 2014). Here, our results also suggested that nuclear PKM2 could serve as a transcriptional cofactor to induce PD-L1 transcription in response to EGF stimulation in hepatocellular carcinoma cells. Accumulating evidences illuminated that posttranslational modifications including phosphorylation and acetylation are critical for the protein localization and functional modulation of PKM2(Yang et al., 2012b; Wang et al., 2017). For instance, the Ser ${ }^{202}$ phosphorylation of PKM2 by AKT1 is essential for the nuclear localization of PKM2 protein under IGF-1 stimulation (Park et al., 2016). Acetyltransferase p300 could acetylate PKM2 at Lys ${ }^{433}$, leading to the accumulation PKM2 in the nucleus and the increases of both tyrosine and threonine kinase activities (Lv et al., 2013). Especially, Yang et al. (2012b) have found that phosphorylation of PKM2 at Ser ${ }^{37}$ by ERK1/2 promotes the translocation of PKM2 to the nucleus upon EGFR activation. Consistent with Yang report, we also demonstrated that $\mathrm{Ser}^{37}$-phosphorylated PKM2 is vital for PKM2 nucleus localization in HCC. Meanwhile, we believe ERK1/2 may be also responsible for the phosphorylation of PKM2 at $\mathrm{Ser}^{37}$ in HCC cells.

Histone $\mathrm{H} 3$ phosphorylation has been regarded as one of the most frequent epigenetic modifications that affects chromatin structure and gene transcription (Cerutti and Casas-Mollano, 2009). For example, phosphorylation of histone H3 at $\mathrm{Ser}^{10}$ was required for AP-1 activation in nasopharyngeal carcinoma ( $\mathrm{Li}$ et al., 2013); phosphorylation $\mathrm{H} 3 \mathrm{Thr}^{45}$ by Akt has been reported to facilitate transcriptional termination in response to DNA damage (Hurd et al., 2009); histone H3-Thr ${ }^{11}$ phosphorylation induced by PKM2 is required for cyclin D1 and c-Myc expression 

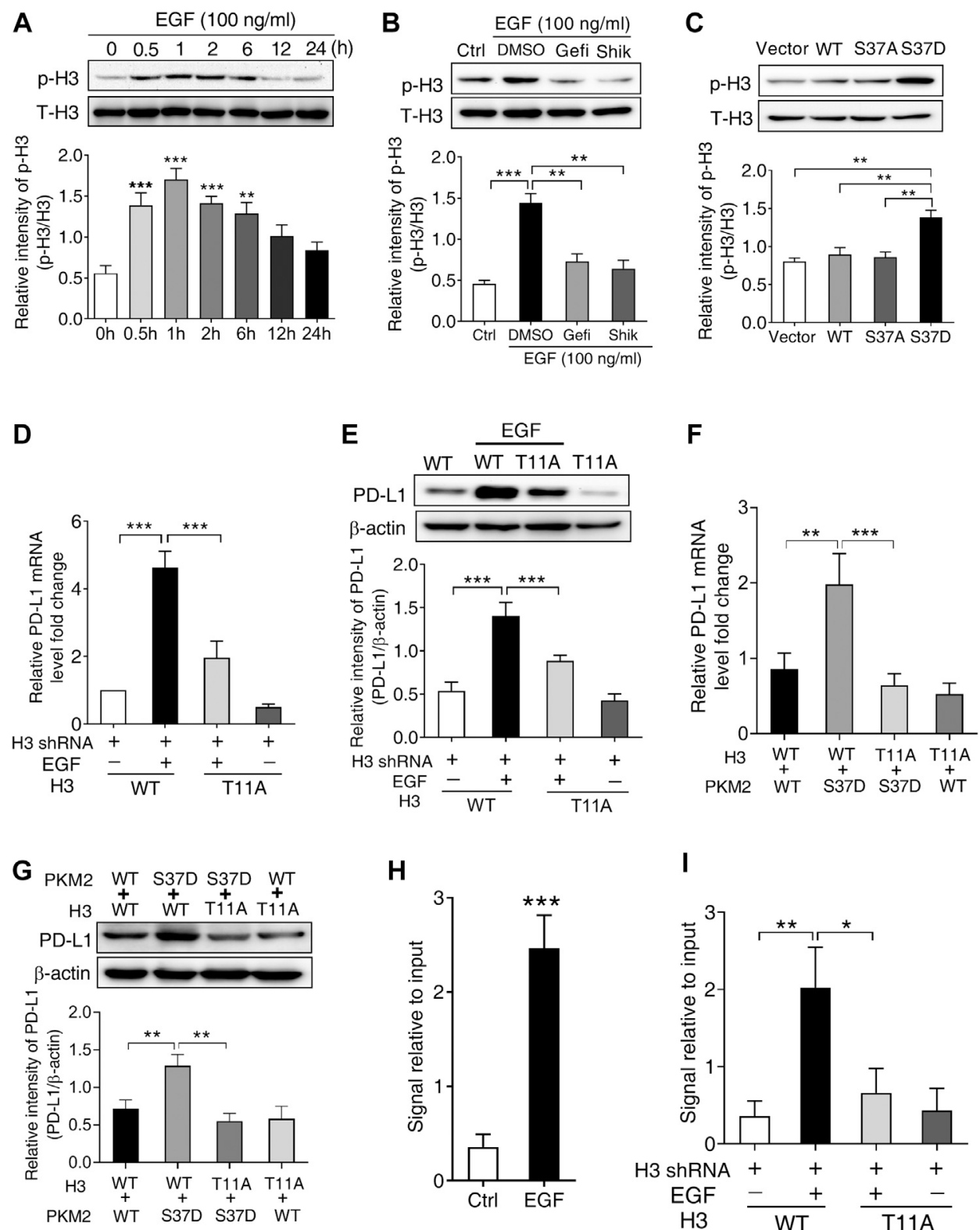

I

FIGURE 5|PKM2-induced phosphorylation of histone $\mathrm{H} 3$ at Thr ${ }^{11}$ is required for EGF-mediated PD-L1 transcription in SNU-368 cells. (A) EGF treatment induced a significant increase in $\mathrm{H} 3 \mathrm{Thr}^{11}$ phosphorylation in SNU-368 cells. ${ }^{* *} p<0.01$, ${ }^{* *} p<0.001$, one-way ANOVA, $n=5$ independent experiments per group, (B) EGFinduced H3-Thr ${ }^{11}$ phosphorylation was attenuated by Gefitinib and shikonin after 1 h co-incubation in SNU-368 cells, ${ }^{* *} p<0.01,{ }^{* * *} p<0.001$, one-way ANOVA, $n=5$ independent experiments per group, (C) expression of the phosphorylation-mimic PKM2 S37D mutant increased H3-Thr ${ }^{11}$ phosphorylation compared with the WT PKM2 or the S37A mutant in SNU-368 cells. ${ }^{* *} p<0.01$, one-way ANOVA, $n=5$ independent experiments per group, (D and E) Reconstituted expression of RNAiresistant histone H3-T11A abrogated EGF-induced the mRNA, (D), and protein (E) expression of PD-L1 in endogenous H3-depleted SNU-368 cells. At $24 \mathrm{~h}$ posttransfection, cells were incubated in the presence or absence of $100 \mathrm{ng} / \mathrm{ml}$ EGF for $12 \mathrm{~h}{ }^{\star * *} p<0.001$, one-way ANOVA, $n=5$ independent experiments per group (F and G) Reconstituted expression of WT histone H3 and PKM2 S37D could induce PD-L1 mRNA (F) and protein (G) expression which could be blocked when WT histone $\mathrm{H} 3$ was replaced with histone $\mathrm{H} 3 \mathrm{~T} 11 \mathrm{~A}$ mutant in endogenous histone H3-depleted SNU-368 cells. ${ }^{* *} p<0.01$, ${ }^{\star * *} p<0.001$, one-way ANOVA, $n=5$ independent experiments per group (H) ChIP analysis showed that EGF treatment for $6 \mathrm{~h}$ resulted in enhanced H3-Thr ${ }^{11}$ phosphorylation at the PD-L1 promoter in SNU-368 cells. ${ }^{*} p<0.01$, a two-tailed unpaired $t$-test, $n=5$ independent experiments per group (I) ChIP analysis showed reconstituted expression of histone H3 T11A mutant abrogated EGF-induced enhanced H3-Thr ${ }^{11}$ phosphorylation at the PD-L1 promoter in endogenous histone H3-depleted SNU-368 cells.

under EGF stimulation (Yang et al., 2012a). In support of these observations, our results suggested that PKM2-mediated histone $\mathrm{H} 3-\mathrm{Thr}^{11}$ phosphorylation participated in EGF-induced PD-L1 transcriptional expression. Interestingly, several studies suggested that histone $\mathrm{H} 3$ acetylation also play a key role in the regulation of PD-L1 gene expression in cancer cells (Lei et al., 2015; Wang et al., 2020). Given that the process of $\mathrm{H} 3$ phosphorylation usually recruits a histone modifying enzyme that would in turn generate 

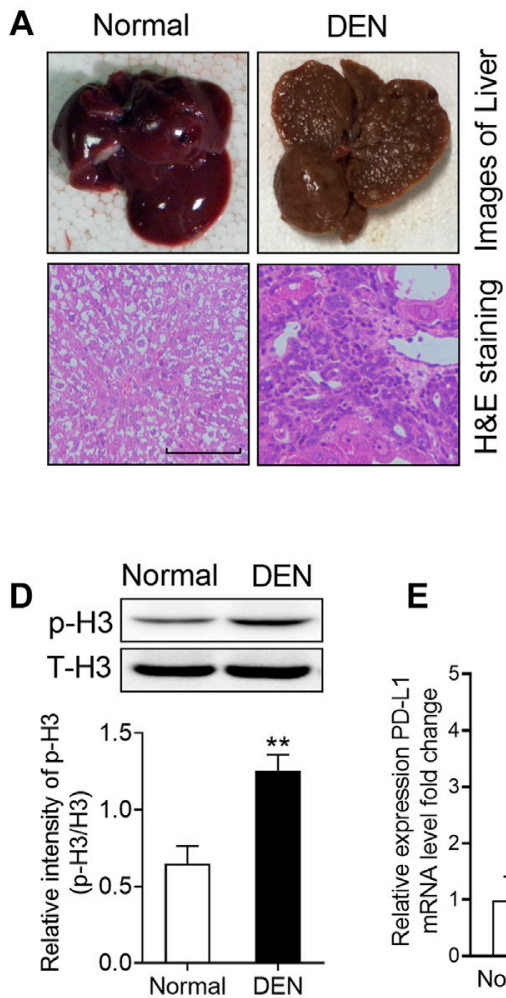

E

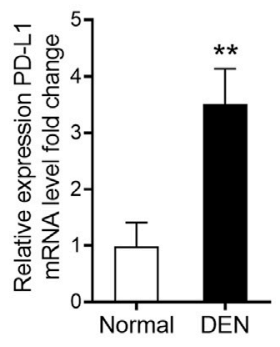

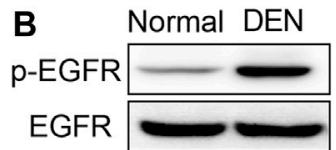

밈

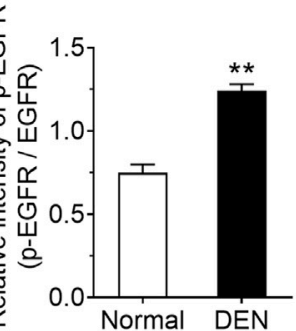

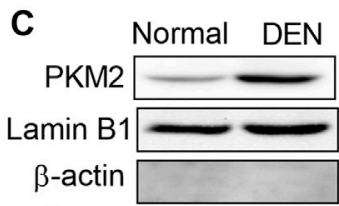

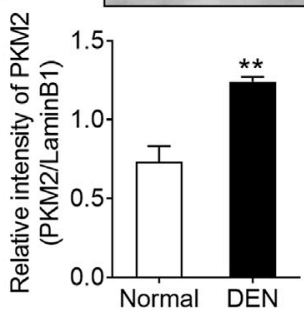

FIGURE 6 | DEN treatment induced a significant upregulation of phospho-EGFR, phospho-H3, and PKM2 nuclear accumulation in rat livers. (A) Top, representative photos of livers from normal and DEN-treated rats; bottom, representative images of H\&E-stained livers. (B) The phosphorylational level of EGFR at Tyr $^{1068}$ was increased in the livers of DEN-treated rats. ${ }^{* *} p<0.01$, two-tailed unpaired t-test, $n=8$ rats per group. (C) The expression of PKM2 nuclear protein was upregulated in the livers of DEN-treated rats. Lamin B1 was used as an internal control, and $\beta$-actin was used as a negative control. ${ }^{* \star} p<0.01$, two-tailed unpaired $t$-test, $n=8$ rats per group. (D) The phosphorylational level of H3-Thr ${ }^{11}$ was increased in the livers of DEN-treated rats. ${ }^{* *} p<0.01$, two-tailed unpaired $t$-test, $n=8$ rats per group. (E,F) The expression of PD-L1 mRNA (E) and protein (F) was increased in the livers of DEN-treated rats. ${ }^{* *} p<0.01,{ }^{* \star *} p<0.001$, two-tailed unpaired t-test, $n=8$ rats per group. (G) ChIP analyses showed that DEN administration resulted in enhanced $\mathrm{H} 3-\mathrm{Thr}^{11}$ phosphorylation at the PD-L1 promoter in rats. ${ }^{* *} p<0.01$, two-tailed unpaired $t$-test, $n=8$ rats per group.

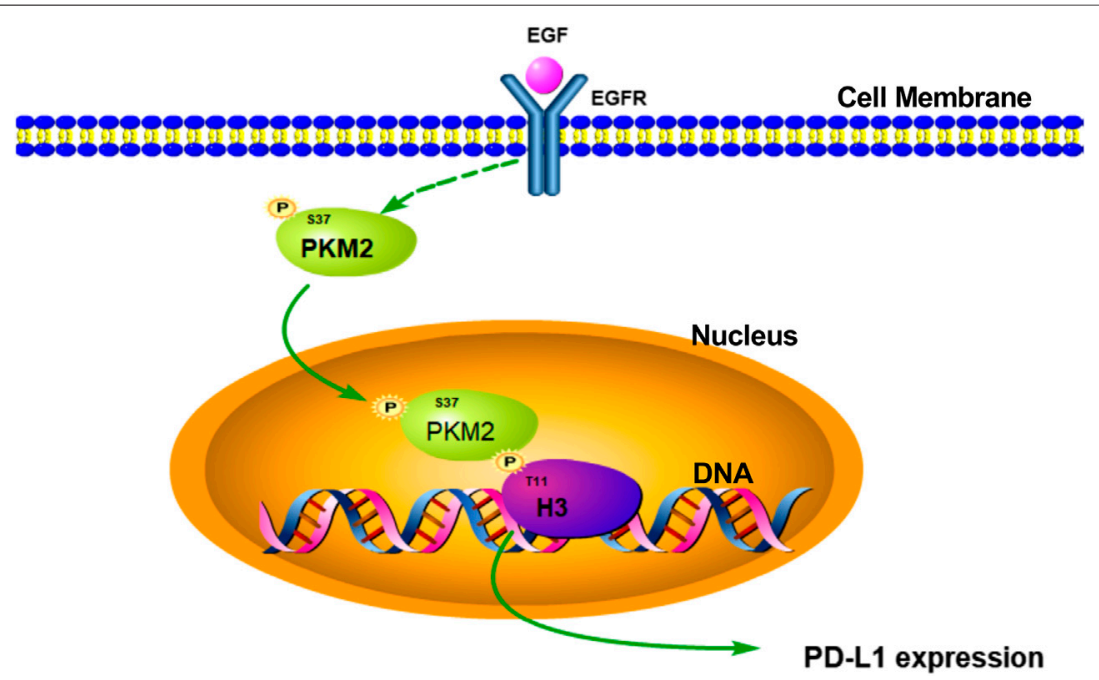

FIGURE 7 | Schematic representation of the activation of EGF induced PD-L1 transcription in hepatocellular carcinoma cells. EGF stimulation induced PKM2 phosphorylation at $\mathrm{Ser}^{37}$ site. Then, the phosphorylated PKM2 translocates into the nucleus to phosphorylate histone H3 at Thr ${ }^{11}$, leading to PD-L1 transcription in HCC. 
the second modification (Cheung et al., 2000; Yang et al., 2012a), we supposed histone $\mathrm{H} 3$ acetylation may be also involved in EGFinduced PD-L1 expression in HCC cells. In line with this opinion, Yang et al. (2012a) found that $\mathrm{H} 3-\mathrm{Thr}^{11}$ phosphorylation induced by EGF is required for histone deacetylase 3 (HDAC3) disassociation from some gene promoters and subsequent acetylation of histone $\mathrm{H} 3$ at Lys ${ }^{9}$. Notably, a recent study suggested that enhancer of zeste homolog 2 (EZH2) can suppress PD-L1 expression by directly upregulating H3K27me3 levels at CD274 (encoding PD-L1) promoter regions in hepatoma cells (Xiao et al., 2019). Combined with Dong et al. (2018) findings that EGF can promote EZH2 expression in human lens epithelial cells (HLECs), therefore, we cannot exclude that EGF can regulate PD-L1 expression through inducing EZH2 overexpression in HCC.

In conclusion, our study firstly suggested that EGF could induce PKM2 phosphorylation at $\mathrm{Ser}^{37}$ and translocation of the PKM2 protein to the nucleus, the nuclear PKM2 then phosphorylates histone $\mathrm{H} 3$ at $\mathrm{Thr}^{11}$ and the subsequent expression of PD-L1 in HCC (Figure 7). Furthermore, these results also revealed that targeting PKM2 or histone $\mathrm{H} 3-\mathrm{Thr}^{11}$ may be an effective treatment approach for HCC in the future.

\section{DATA AVAILABILITY STATEMENT}

The raw data supporting the conclusions of this article will be made available by the authors, without undue reservation.

\section{REFERENCES}

Azoitei, N., Becher, A., Steinestel, K., Rouhi, A., Diepold, K., Genze, F., et al. (2016). PKM2 promotes tumor angiogenesis by regulating HIF-1alpha through NFkappaB activation. Mol. Cancer 15, 3. doi:10.1158/1538-7445.am2017-1809

Berasain, C., and Avila, M. A. (2014). The EGFR signalling system in the liver: from hepatoprotection to hepatocarcinogenesis. J. Gastroenterol. 49, 9-23. doi:10. 1007/s00535-013-0907-x

Bhardwaj, A., and Das, S. (2016). SIRT6 deacetylates PKM2 to suppress its nuclear localization and oncogenic functions. Proc. Natl. Acad. Sci. U.S.A. 113, E538-E547. doi:10.1073/pnas.1520045113

Bi, S., Wei, Q., Zhao, Z., Chen, L., Wang, C., and Xie, S. (2019). Wee1 inhibitor AZD1775 effectively inhibits the malignant phenotypes of esophageal squamous cell carcinoma in vitro and in vivo. Front. Pharmacol. 10, 864. doi:10.3389/fphar.2019.00864

Cerutti, H., and Casas-Mollano, J. A. (2009). Histone H3 phosphorylation: universal code or lineage specific dialects? Epigenetics 4, 71-75. doi:10.4161/ epi.4.2.7781

Chen, D. P., Ning, W. R., Jiang, Z. Z., Peng, Z. P., Zhu, L. Y., Zhuang, S. M., et al. (2019a). Glycolytic activation of peritumoral monocytes fosters immune privilege via the PFKFB3-PD-L1 axis in human hepatocellular carcinoma. J. Hepatol. 71, 333-343. doi:10.1016/j.jhep.2019.04.007

Chen, M., Sharma, A., Lin, Y., Wu, Y., He, Q., Gu, Y., et al. (2019b). Insluin and epithelial growth factor (EGF) promote programmed death ligand 1(PD-L1) production and transport in colon cancer stem cells. BMC Cancer 19, 153. doi:10.1186/s12885-019-5364-3

Chen, S., Youhong, T., Tan, Y., He, Y., Ban, Y., Cai, J., et al. (2019c). EGFR-PKM2 signaling promotes the metastatic potential of nasopharyngeal carcinoma through induction of FOSL1 and ANTXR2. Carcinogenesis 41, 863-864. doi:10.1093/carcin/bgaa023

\section{ETHICS STATEMENT}

The animal study was reviewed and approved by All animal procedures were performed in accordance with the guidelines of the Institutional Animal Care and Use Committee of Henan University.

\section{AUTHOR CONTRIBUTIONS}

XW performed performed Western blot analysis and real time PCR. CL and XY performed all animal experiments. F-YL, W-QL, and S-HP and carried out Chromatin Immunoprecipitation. $\mathrm{R}-\mathrm{HY}$ and ZZ participated in the data analysis. JM, S-QX and $\mathrm{DF}$, participated in the design of the study and manuscript writing. All authors read and approved the final manuscript.

\section{FUNDING}

This work was supported by the National Natural Science Foundation of China (Grant Nos. 81701110 and 81772832), Program for Innovative Research Team (in Science and Technology in University of Henan Province) (Grant No. 19IRTSTHN004), Scientific Research Cultivating Program for Young Talents in Henan Medical School (Grant No. 2019016), Guangdong Provincial Key Laboratory of Drug Non-clinical Evaluation and Research (Grant No. 2018B030323024).

Cheung, P., Tanner, K. G., Cheung, W. L., Sassone-Corsi, P., Denu, J. M., and Allis, C. D. (2000). Synergistic coupling of histone H3 phosphorylation and acetylation in response to epidermal growth factor stimulation. Mol. Cell 5, 905-915.

Dong, N., Xu, B., and $\mathrm{Xu}, \mathrm{J}$. (2018). EGF-mediated overexpression of myc attenuates miR-26b by recruiting HDAC3 to induce epithelial-mesenchymal transition of lens epithelial cells. BioMed Res. Int. 2018, 7148023. doi:10.1155/ 2018/7148023

Du, L., Zhang, B., Lei, Y., Wang, S., and Jin, Y. (2016). Long-circulating and livertargeted nanoassemblies of cyclic phosphoryl N-dodecanoyl gemcitabine for the treatment of hepatocellular carcinoma. Biomed. Pharmacother. 79, 208-214. doi:10.1016/j.biopha.2016.02.024

Guo, C. Y., Zhu, Q., Tou, F. F., Wen, X. M., Kuang, Y. K., and Hu, H. (2019). The prognostic value of PKM2 and its correlation with tumour cell PD-L1 in lung adenocarcinoma. BMC Cancer 19, 289. doi:10.1186/s12885-019-5519-2

Hurd, P. J., Bannister, A. J., Halls, K., Dawson, M. A., Vermeulen, M., Olsen, J. V., et al. (2009). Phosphorylation of histone H3 Thr-45 is linked to apoptosis. J. Biol. Chem. 284, 16575-16583. doi:10.1074/jbc.m109.005421

Lanaya, H., Natarajan, A., Komposch, K., Li, L., Amberg, N., Chen, L., et al. (2014). EGFR has a tumour-promoting role in liver macrophages during hepatocellular carcinoma formation. Nat. Cell Biol. 16, 972-977. doi:10.3410/f.718551160. 793577027

Langhans, B., Nischalke, H. D., Kramer, B., Dold, L., Lutz, P., Mohr, R., et al. (2019). Role of regulatory $\mathrm{T}$ cells and checkpoint inhibition in hepatocellular carcinoma. Cancer Immunol. Immunother. CII 68, 2055-2066. doi:10.31525/ ct1-nct04134559

Lei, G. S., Zhang, C., and Lee, C. H. (2015). Myeloid-derived suppressor cells impair alveolar macrophages through PD-1 receptor ligation during Pneumocystis pneumonia. Infect. Immun. 83, 572-582. doi:10.1128/iai.02686-14

Li, B., Huang, G., Zhang, X., Li, R., Wang, J., Dong, Z., et al. (2013). Increased phosphorylation of histone $\mathrm{H} 3$ at serine 10 is involved in Epstein-Barr virus 
latent membrane protein-1-induced carcinogenesis of nasopharyngeal carcinoma. BMC Cancer 13, 124. doi:10.1186/1471-2407-13-124

Li, W., Hou, J. Z., Niu, J., Xi, Z. Q., Ma, C., Sun, H., et al. (2018a). Akt1 inhibition promotes breast cancer metastasis through EGFR-mediated beta-catenin nuclear accumulation. Cell Commun. Signal. CCS 16, 82. doi:10.1186/ s12964-018-0295-1

Li, X., Lian, Z., Wang, S., Xing, L., and Yu, J. (2018b). Interactions between EGFR and PD-1/PD-L1 pathway: implications for treatment of NSCLC. Cancer Lett. 418, 1-9. doi:10.1016/j.canlet.2018.01.005

Li, Y. H., Li, X. F., Liu, J. T., Wang, H., Fan, L. L., Li, J., et al. (2018c). PKM2, a potential target for regulating cancer. Gene 668, 48-53. doi:10.1016/j.gene.2018. 05.038

Liao, H., Chen, W., Dai, Y., Richardson, J. J., Guo, J., Yuan, K., et al. (2019). Expression of programmed cell death-ligands in hepatocellular carcinoma: correlation with immune microenvironment and survival outcomes. Front. Oncol. 9, 883. doi:10.3389/fonc.2019.00883

Liu, F., Ma, F., Wang, Y., Hao, L., Zeng, H., Jia, C., et al. (2017). PKM2 methylation by CARM1 activates aerobic glycolysis to promote tumorigenesis. Nat. Cell Biol. 19, 1358-1370. doi:10.1158/1538-7445.am2018-2418

Liu, P., Chen, L., and Zhang, H. (2018a). Natural killer cells in liver disease and hepatocellular carcinoma and the NK cell-based immunotherapy. J. Immunol. Res. 8, 1206737. doi:10.1155/2018/1206737

Liu, T., Zhang, X., Zhang, Y., Hou, J., Fang, D., Sun, H., et al. (2018b). Sulfation disposition of liquiritigenin in SULT1A3 overexpressing HEK293 cells: the role of breast cancer resistance protein (BCRP) and multidrug resistance-associated protein 4 (MRP4) in sulfate efflux of liquiritigenin. Eur. J. Pharmaceut. Sci. : Off. J. Eur. Fed. Pharm. Sci. 124, 228-239. doi:10.1016/j.ejps.2018.08.041

Lv, L., Xu, Y. P., Zhao, D., Li, F. L., Wang, W., Sasaki, N., et al. (2013). Mitogenic and oncogenic stimulation of K433 acetylation promotes PKM2 protein kinase activity and nuclear localization. Mol. Cell 52, 340-352. doi:10.1016/j.molcel. 2013.09.004

Lv, W. W., Liu, D., Liu, X. C., Feng, T. N., Li, L., Qian, B. Y., et al. (2018). Effects of PKM2 on global metabolic changes and prognosis in hepatocellular carcinoma: from gene expression to drug discovery. BMC Cancer 18, 1150. doi:10.1186/ s12885-018-5023-0

Ma, G., Liang, Y., Chen, Y., Wang, L., Li, D., Liang, Z., et al. (2020). Glutamine deprivation induces PD-L1 expression via activation of EGFR/ERK/c-Jun signaling in renal cancer. Mol. Canc. Res. : MCR 18, 324-339. doi:10.1158/ 1541-7786.mcr-19-0517

Macek Jilkova, Z., Aspord, C., and Decaens, T. (2019). Predictive factors for response to PD-1/PD-L1 checkpoint inhibition in the field of hepatocellular carcinoma: current status and challenges. Cancers 11. doi:10.3390/cancers11101554

Maennling, A. E., Tur, M. K., Niebert, M., Klockenbring, T., Zeppernick, F., Gattenlohner, S., et al. (2019). Molecular targeting therapy against EGFR family in breast cancer: progress and future potentials. Cancers 11, 27-33. doi:10.3390/ cancers 11121826

Mantovani, S., Oliviero, B., Varchetta, S., Mele, D., and Mondelli, M. U. (2020). Natural killer cell responses in hepatocellular carcinoma: implications for novel immunotherapeutic approaches. Cancers 12, 926. doi:10.3390/cancers12040926

Mocan, T., Sparchez, Z., Craciun, R., Bora, C. N., and Leucuta, D. C. (2019). Programmed cell death protein-1 (PD-1)/programmed death-ligand-1 (PD-L1) axis in hepatocellular carcinoma: prognostic and therapeutic perspectives. Clin. Transl. Oncol. 21, 702-712. doi:10.1007/s12094-018-1975-4

Nie, X., Liu, Y., Chen, W. D., and Wang, Y. D. (2018). Interplay of miRNAs and canonical Wnt signaling pathway in hepatocellular carcinoma. Front. Pharmacol. 9, 657. doi:10.3389/fphar.2018.00657

Palsson-McDermott, E. M., Dyck, L., Zaslona, Z., Menon, D., McGettrick, A. F., Mills, K. H. G., et al. (2017). Pyruvate kinase M2 is required for the expression of the immune checkpoint PD-L1 in immune cells and tumors. Front. Immunol. 8, 1300. doi:10.3389/fimmu.2017.01300
Park, Y. S., Kim, D. J., Koo, H., Jang, S. H., You, Y. M., Cho, J. H., et al. (2016). AKTinduced PKM2 phosphorylation signals for IGF-1-stimulated cancer cell growth. Oncotarget 7, 48155-48167. doi:10.18632/oncotarget.10179

Patel, R., and Leung, H. Y. (2012). Targeting the EGFR-family for therapy: biological challenges and clinical perspective. Curr. Pharmaceut. Des. 18, 2672-2679. doi:10.2174/138161212800626148

Su, L., Guo, W., Lou, L., Nie, S., Zhang, Q., Liu, Y., et al. (2020). EGFR-ERK pathway regulates CSN6 to contribute to PD-L1 expression in glioblastoma. Mol. Carcinog. 59, 520-532. doi:10.1002/mc.23176

Wang, H., Fu, C., Du, J., Wang, H., He, R., Yin, X., et al. (2020). Enhanced histone $\mathrm{H} 3$ acetylation of the PD-L1 promoter via the COP1/c-Jun/HDAC3 axis is required for PD-L1 expression in drug-resistant cancer cells. J. Exp. Clin. Canc. Res.: CR (Clim. Res.) 39, 29. doi:10.1186/s13046-020-1536-x

Wang, Y., Liu, J., Jin, X., Zhang, D., Li, D., Hao, F., et al. (2017). O-GlcNAcylation destabilizes the active tetrameric PKM2 to promote the Warburg effect. Proc. Natl. Acad. Sci. U.S.A. 114, 13732-13737. doi:10.1073/pnas.1704145115

Wong, N., Ojo, D., Yan, J., and Tang, D. (2015). PKM2 contributes to cancer metabolism. Cancer Lett. 356, 184-191. doi:10.1016/j.canlet.2014.01.031

Xiao, G., Jin, L. L., Liu, C. Q., Wang, Y. C., Meng, Y. M., Zhou, Z. G., et al. (2019). EZH2 negatively regulates PD-L1 expression in hepatocellular carcinoma. J. Immunother. Cancer 7, 300. doi:10.7554/elife.40396.005

Xie, M., Yu, Y., Kang, R., Zhu, S., Yang, L., Zeng, L., et al. (2016). PKM2-dependent glycolysis promotes NLRP3 and AIM2 inflammasome activation. Nat. Commun. 7, 13280. doi:10.1038/ncomms 13280

Yang, P., Li, Z., Fu, R., Wu, H., and Li, Z. (2014). Pyruvate kinase M2 facilitates colon cancer cell migration via the modulation of STAT3 signalling. Cell. Signal. 26, 1853-1862. doi:10.1016/j.cellsig.2014.03.020

Yang, W., Xia, Y., Hawke, D., Li, X., Liang, J., Xing, D., et al. (2012a). PKM2 phosphorylates histone $\mathrm{H} 3$ and promotes gene transcription and tumorigenesis. Cell 150, 685-696. doi:10.3410/f.717954063.793460732

Yang, W., Xia, Y., Ji, H., Zheng, Y., Liang, J., Huang, W., et al. (2011). Nuclear PKM2 regulates beta-catenin transactivation upon EGFR activation. Nature 480, 118-122. doi:10.3410/f.14267166.15779340

Yang, W., Zheng, Y., Xia, Y., Ji, H., Chen, X., Guo, F., et al. (2012b). ERK1/2dependent phosphorylation and nuclear translocation of PKM2 promotes the Warburg effect. Nat. Cell Biol. 14, 1295-1304. doi:10.1038/ncb2677

Zhong, F., Cheng, X., Sun, S., and Zhou, J. (2017). Transcriptional activation of PDL1 by Sox 2 contributes to the proliferation of hepatocellular carcinoma cells. Oncol. Rep. 37, 3061-3067. doi:10.3892/or.2017.5523

Zhu, Y., Yang, J., Xu, D., Gao, X. M., Zhang, Z., Hsu, J. L., et al. (2019). Disruption of tumour-associated macrophage trafficking by the osteopontininduced colony-stimulating factor-1 signalling sensitises hepatocellular carcinoma to anti-PD-L1 blockade. Gut 68, 1653-1666. doi:10.1136/ gutjnl-2019-318419

Zou, J., Zhuang, M., Yu, X., Li, N., Mao, R., Wang, Z., et al. (2018). MYC inhibition increases PD-L1 expression induced by IFN-gamma in hepatocellular carcinoma cells. Mol. Immunol. 101, 203-209. doi:10.1016/j.molimm.2018. 07.006

Conflict of Interest: The authors declare that the research was conducted in the absence of any commercial or financial relationships that could be construed as a potential conflict of interest.

Copyright $\odot 2020$ Wang, Liang, Yao, Yang, Zhang, Liu, Li, Pei, Ma, Xie and Fang. This is an open-access article distributed under the terms of the Creative Commons Attribution License (CC BY). The use, distribution or reproduction in other forums is permitted, provided the original author(s) and the copyright owner(s) are credited and that the original publication in this journal is cited, in accordance with accepted academic practice. No use, distribution or reproduction is permitted which does not comply with these terms. 